\title{
Analysis and Prediction of Pavement Settlement Caused by Jacking Construction of Ultra-Shallow Rectangular Shield Frame Bridge
}

\author{
Da Hu $\mathbb{D}^{1},{ }^{1,2}$ Yongsuo Li $\mathbb{D}^{1},{ }^{1}$ Xiaoqiang Liang, ${ }^{1}$ Youping $W u,{ }^{3}$ Sheng Zhang $\mathbb{D}^{1}$ \\ and Qi Yao \\ ${ }^{1}$ School of Civil Engineering, Hunan City University, Yiyang 413000, China \\ ${ }^{2}$ Key Laboratory of Metallogenic Prediction of Nonferrous Metals and Geological Environmental \\ Monitoring Ministry of Education, Central South University, Changsha 410083, China \\ ${ }^{3}$ PowerChian Zhongnan Engineering Co. Ltd., Changsha 410014, China
}

Correspondence should be addressed to Yongsuo Li; liyongsuo@126.com

Received 18 July 2020; Revised 3 October 2020; Accepted 13 October 2020; Published 28 October 2020

Academic Editor: Xinyu Xie

Copyright $(92020 \mathrm{Da} \mathrm{Hu}$ et al. This is an open access article distributed under the Creative Commons Attribution License, which permits unrestricted use, distribution, and reproduction in any medium, provided the original work is properly cited.

The primary purpose of this paper is to analyze and predict the ground settlement law of large-span rectangular shield frame bridge jacking project, to provide a reference for the optimization design and safe construction of similar projects. In this paper, combined with the jacking project of ultra-shallow buried soft soil layer rectangular shield frame bridge, through the on-site monitoring, the settlement deformation law of the longitudinal and transverse sections of the expressway pavement during the jacking construction process is discussed, and the reasons for the large settlement and rebound are analyzed. The basic laws of the road surface settlement with time are summarized. Based on the Kriging spatiotemporal prediction model, the road surface settlement is predicted. The research shows that the transverse settlement trough of the pavement caused by the rectangular shield frame bridge's jacking construction is stable within $15 \mathrm{~m}-20 \mathrm{~m}$ on both sides toward the axis and symmetrical along the coordinate axis and the alignment roughly conforms to the normal distribution. The influence range of settlement trough becomes greater and greater with shield jacking, and the final settlement curve is $\mathrm{W}$-shaped. After comparing the predicted curve with the measured road settlement curve, we found that the two curves are in good agreement, and the prediction result of the Kriging spatiotemporal prediction model is valid, which can reflect the process of road deformation development during the jacking process of the shield.

\section{Introduction}

In recent years, with the advancement of the new-type urbanization strategy in China, urban underground space construction has made a spurt of progress. As the primary carrier of urban infrastructure, underground space plays an increasingly important role in city development, with a swift and violent development momentum. As an underground trenchless technology, rectangular pipe jacking technology has been widely used in open-cut restricted projects such as urban subterranean passages, full pipeline galleries, tunnels passing through important roads, subway stations, and underground commercial complex development. Rectangular pipe jacking projects in recent years include 2010
Lynchburg City, USA, through rectangular jacking tunnel of the railway; 2010 Jinke Road jacking project of East Extension Section of Shanghai Rail Transit Line 2; 2012 Guicheng Station crossing channel project of Nanhai District, Foshan City, China; 2013 Shenzhuang North RoadShangding Road under Zhongzhou Avenue rectangular pipe jacking tunnel project of Zhengzhou City, China; Rectangular Pipe Jacking Project for Intersection Channel from Huaqiang North to Huaxin Metro Station in Shenzhen, China; Pipe Jacking Project for No.1 Street Crossing Channel of Nanhu Station of Nanning Metro Line 1 in 2015. The tunnel constructed by this technology has many advantages, such as shallow buried depth, the high utilization ratio of section, uninterrupted road traffic, no need to 
dismantle various underground pipelines, no noise, and no environmental pollution. Compared with circular pipe jacking tunnels, it can save about $20 \%$ of the space and has better adaptability to shallow soil cover, and pipe joints can also be poured on-site. It represents the development direction of rectangular short tunnel construction technology in the future. However, the section of rectangular pipe jacking tends to be large, which will inevitably change the stress state of surrounding shallow strata during construction, resulting in soil loss and surface deformation, thus affecting ground traffic, especially in jacking projects through expressways. The project supported in this paper is the jacking project of underpass expressway, which belongs to the ultra-shallow burial, and no interruption of expressway traffic is allowed in the construction process. Therefore, it is of considerable significance to study the law of soil deformation caused by jacking construction of ultrashallow buried broad cross section rectangular shield, explore the control measures of surface deformation, and maximize the protection of the surrounding environment for improving the adaptability of rectangular pipe jacking in the complex urban environment.

In the 1970s, Japan first successfully applied rectangular pipe jacking technology to constructing the Tokyo Underground Connection Channel [1]. Since the 1990s, rectangular pipe jacking technology has been gradually applied in China. Based on the construction of a circular pipe jacking or rectangular shield, some scholars at home and abroad have studied the soil deformation caused by rectangular pipe jacking. O'Reilly and Rogers [2] were the first to study the surface deformation caused by pipe jacking, and Rogers and Chapman [3] and Marshall [4] explored the above problems. Shen et al. [5] Successfully applied real-time monitoring for the construction of a microtunnel by continuous pipe jacking method, summarized the relationship between ground reaction and construction parameters, and discussed the technical problems and lessons faced by the project based on monitoring data. Considering the four main factors that may cause ground movement during pipe jacking, Cheng et al. [6] proposed a new model based on Mindlin solution and considered the four factors and gave the theoretical solution of ground motion caused by fluid pressure.

The above studies are all about circular pipe jacking, while the research on rectangular pipe jacking is mainly started from Matsumoto et al. [7]. Landers and Large [8] introduced the British four-lane underground road, which underpass railway tracked project, and discussed the challenges faced by project designers and solutions. Wang et al. [9] carried out a three-dimensional numerical simulation of the response of long-span box culvert jacking into a highway, analyzed the monitoring results of the highway and the problems encountered in the actual construction process, and discussed the causes and influencing factors of large deformation of highway pavement. Wang [10] used Mindlin solution and random medium theory to derive the formula for calculating the soil deformation caused by rectangular pipe jacking construction under comprehensive factors and made a simple theoretical analysis of the three-dimensional soil deformation caused by rectangular pipe jacking. In Deng et al. [11], relying on practical engineering projects, the mechanism of surface heave and local deformation caused by rectangular pipe jacking were analyzed in depth, and the main controlling factors of surface heave and subsidence were found. Based on the modified Peck formula, Zhang et al. [12] proposed a method for predicting surface settlement of rectangular shield tunnel construction. Li [13] studied the critical technologies of a rectangular pipe jacking machine and horseshoe TBM in the design optimization of shield tunneling in the Loess stratum. Engineering practice shows that noncircular TBMS has excellent advantages in construction progress, settlement control, and space utilization. Taking a quasirectangular shield tunnel as background, Si et al. [14] summarized the fundamental law of vertical ground deformation, which was caused by rectangular shield tunnel construction. According to the Riemann theorem and complex variable theory, Li and Liu [15] established a conformal mapping function and derived a stress calculation formula for a shallow rectangular tunnel. Di Mascio et al. [16] established a finite element model to discuss the influence of vertical irregularity bridge expansion joints on upper traffic under traffic loads, which provides exciting research ideas for the study of this article. Based on Mindlin's displacement solution and random medium theory, Wei et al. [17] consider the influence of various factors to study the vertical soil displacement caused by rectangular shield construction. Based on Mindlin's solution of elasticity and considering the interaction of four factors, Zhang et al. [18] used a numerical integration method and the superposition principle to analyze the surface deformation. Based on practical engineering, $\mathrm{Xu}$ et al. [19] revealed the deformation mode of soil around rectangular pipe jacking tunnel under grouting pressure, deduced the calculation method of vertical deformation of soil caused by grouting filling, and gave the calculation formula of consolidation settlement after construction caused by dissipation of excess pore water in the soil in disturbance range.

The mechanical mechanism and surface deformation of rectangular pipe jacking construction are analyzed by theoretical analysis, model test, and numerical simulation. However, there is not a very accurate and perfect theoretical method for predicting ground deformation in rectangular pipe jacking construction. Therefore, based on the jacking project of the rectangular shield frame bridge in ultra-shallow soft soil stratum, this paper summarizes the fundamental law of pavement settlement with time by monitoring data of fieldtest section, introduces the geostatistics method, and predicts the settlement and deformation of the expressway pavement based on the Kriging spatiotemporal prediction model.

\section{Engineering Background}

2.1. Project Overview. The West extension of Liuye Avenue has two skew frame bridge with a clearance of $18.2 \mathrm{~m} * 6.0 \mathrm{~m}$ at $K 7+081.113$ in the road center. The skew between the frame bridge and Chang-Zhang Expressway is 63.881 degrees. Each frame bridge's total length is $51 \mathrm{~m}$, and the thickness of the overburden soil of the frame bridge is about $2.000 \mathrm{~m}-2.683 \mathrm{~m}$. There are three relays in operation from the frame bridge. The frame bridge is prefabricated 
according to four sections, each of which is $12 \mathrm{~m}, 13 \mathrm{~m}, 13 \mathrm{~m}$, and $13 \mathrm{~m}$ in length. The structure is designed as P8 grade C40 impervious reinforced concrete. The thickness of the roof and sidewall of the frame bridge is $130 \mathrm{~cm}$, and the thickness of the floor is $140 \mathrm{~cm}$. The distance between the two frame bridges is $150 \mathrm{~cm}$. The frame bridge is constructed by setting up the working pit, back wall, slide board, and shield support on site. Construction technology of "skew, skew construction, and top-right" is adopted. The joint settlement width of each frame bridge is $4 \mathrm{~cm}$. According to this project's design document, the maximum jacking force of the rectangular frame bridge is $48430.60 \mathrm{kN}$. In the process of construction, the friction coefficient between the outside of the frame bridge and the soil must be determined by relevant tests. In order to control the jacking speed, it is necessary to adjust and check the jacking force according to the site conditions.

In the construction of this project, the pavement traffic of Chang-Zhang Expressway cannot be interrupted, but jacking construction will disturb the subgrade and cause settlement. If the settlement is too large, the traffic safety will be affected. In view of the fact that only the lane at the front end of the shield machine is closed in the traffic guidance scheme of the expressway (i.e., the emergency lane is closed in turn, the emergency lane is opened and the traffic lane is closed, the traffic lane and the overtaking lane are closed, the overtaking lane from Changsha to Zhangjiajie is opened, and the overtaking lane from Zhangjiajie to Changsha is closed, etc.), and the factors such as relatively thick overburden on the right side, driving conditions, and operation safety are considered. Therefore, the jacking construction of the right frame bridge is carried out first. The layout of the project is shown in Figures 1-3.

2.2. Engineering Geology. According to the geological histogram, the whole frame bridge is located in the expressway embankment's filling soil. From top to bottom, it is miscellaneous fill (brown mixed with variegated color, slightly dense to medium dense, and slightly wet to wet). The average thickness of the whole bridge is $18.56 \mathrm{~m}$. The measured foundation bearing capacity [fa0] $=140 \mathrm{kPa}$, internal cohesion $C=16 \mathrm{kPa}$, internal friction angle $\varphi=15^{\circ}$, and silty clay is brown-yellow, grayish-yellow, and plastic hard plastic. The measured foundation bearing capacity $[\mathrm{fa} 0]=140 \mathrm{kPa}$, internal cohesion $C=20 \mathrm{kPa}$, and internal friction angle $\varphi=18^{\circ}$. The working pit and the frame bridge of ChangZhang expressway are filled subgrade, where the geological conditions do not meet the requirements of jacking the frame bridge, and the bearing capacity of the foundation must meet the minimum requirement of $200 \mathrm{kPa}$. Therefore, to ensure the safety of the frame bridge, it is necessary to reinforce the working pit and the basement of the ChangZhang Expressway before the working pit's slide plate construction to ensure the safety of the frame bridge.

The specific reinforcement measures are as follows: firstly, the backpressure platform with a length of $9 \mathrm{~m}$ is filled at the exit of the frame bridge; secondly, the concrete door frame beam is set at the entrance and exit of the jacking, and the door frame column is set at both ends and in the middle (the door frame column is actually a bored pile with $d=0.8 \mathrm{~m}$ ); finally, a row of $D=1.2 \mathrm{~m}$ concrete cast-in-place piles with a spacing of $3.0 \mathrm{~m}$ and a crown of $1.5 \mathrm{~m} \times 1.5 \mathrm{~m}$ is poured on the top of the platform beam, and crown beam and door frame beam are set every $3 \mathrm{~m}$ to support the door frame beam.

The frame bridge is constructed with shield support onsite and matching jacks between relays and at the end of the frame bridge.

\section{Monitoring and Analysis of Pavement Settlement}

3.1. On-Site Monitoring Scheme. Since only the front lane of shield tunneling is enclosed in the highway traffic guiding scheme, according to the monitoring scheme and considering the safety of the monitoring personnel under the driving conditions, the measuring points are arranged at the edge of the guardrail of the emergency lane on both sides and the middle partition zone, and 3-4 test sections are arranged. The original datum points are arranged in the relative coordinate system outside the jacking influence roadbed, and two are set to check each other. According to third-class leveling's technical requirements, the monitoring points are measured point by point by using the leveling instrument and tower ruler. The monitoring of this project lasts until the jacking is completed; that is to say, 48 days later, the rectangular frame bridge has completed the jacking process. The layout of the monitoring points is shown in Figure 4.

\subsection{Analysis of Pavement Settlement}

3.2.1. Settlement Law of Longitudinal Pavement. Through on-site monitoring, this paper selects seven representative sections on the left sheet for research (Section 1 7 in Figure 2) and makes curves for the change of accumulated settlement value of each monitoring point along the time longitudinally, as shown in Figures 5 8. The curve line of the change of each longitudinal measuring point's accumulated settlement value along the jacking direction is shown in Figures 9-11. The point in the curve below the cumulative warning value indicates that it has exceeded the cumulative warning value (the designed warning value is $-20 \mathrm{~mm}$, which was synthetically determined according to the upper limit of levelness of subgrade base $(12 \mathrm{~mm})$ and pavement $(8 \mathrm{~mm})$ in the "Standard for Quality Inspection and Evaluation of Highway Engineering" of China).

From Figures 5-11, it can be seen that, during the jacking construction of the left frame bridge, the final measured points of excessive settlement value are $Z 1, Z 4, Z 6, Z 5^{\prime}, Z 6^{\prime}$, $Z 1^{\prime}, Z 2^{\prime}$, and $Z 3^{\prime}$. There are $Z 2$ and $Z 5$ measuring points where the accumulated settlement value in the historical period exceeds the limit, and the final accumulated settlement value does not exceed the limit. There are $Z 2, Z 3, Z 5$, and $Z 4^{\prime}$, which have not exceeded the accumulated settlement value limit.

Combined with the field situation and monitoring data analysis, it can be seen that, during the left frame bridge's 


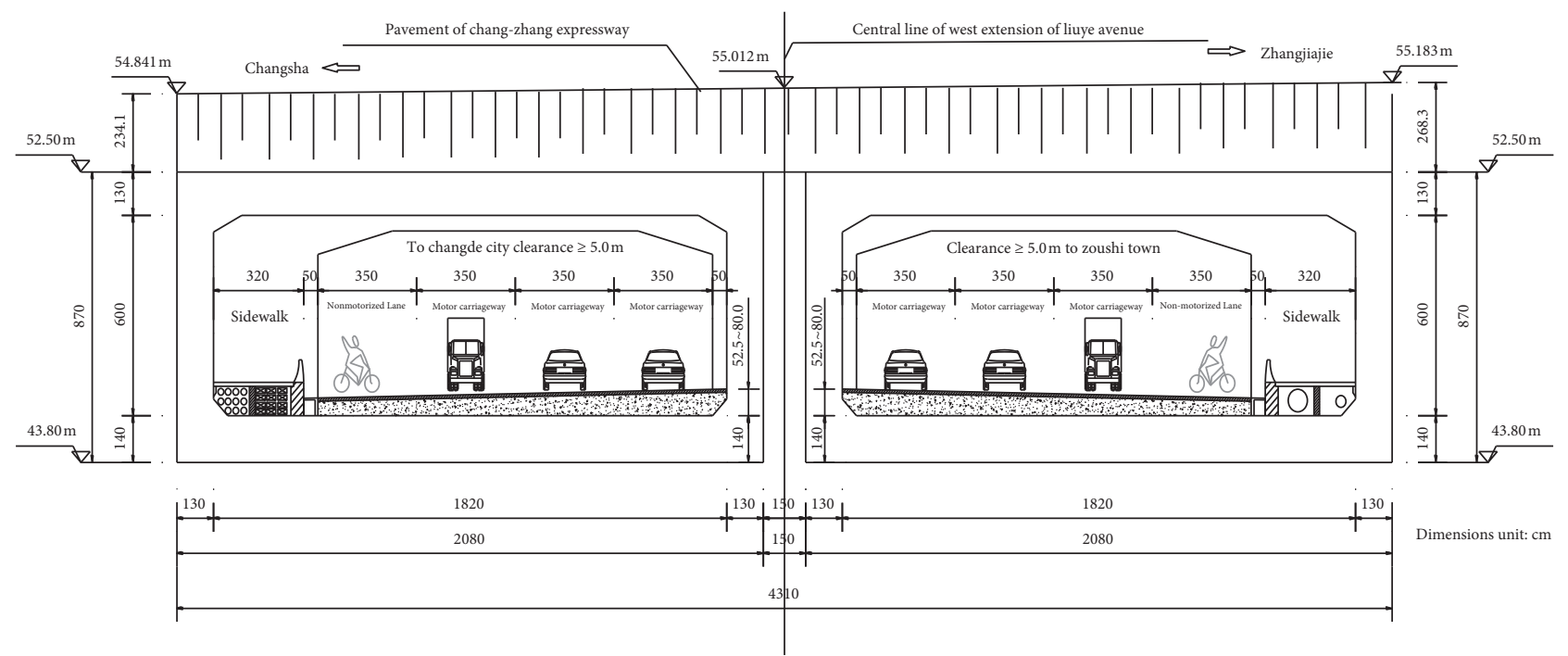

FIgURE 1: The general layout of the rectangular shield frame bridge along with the west extension of Liuye Avenue.

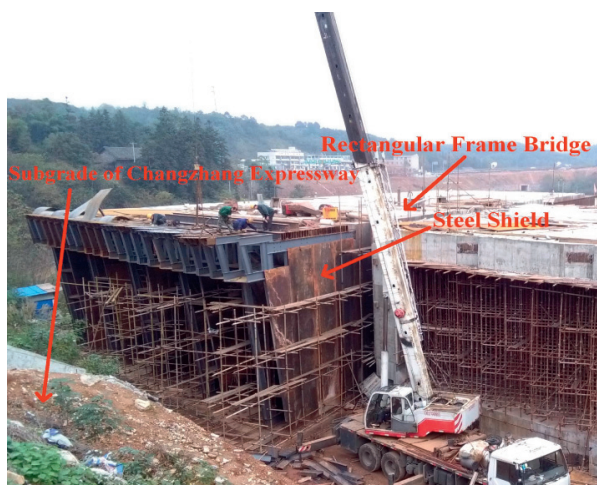

(a)

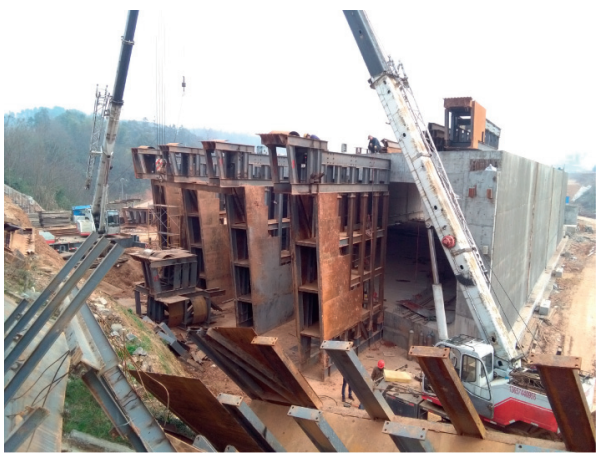

(c)

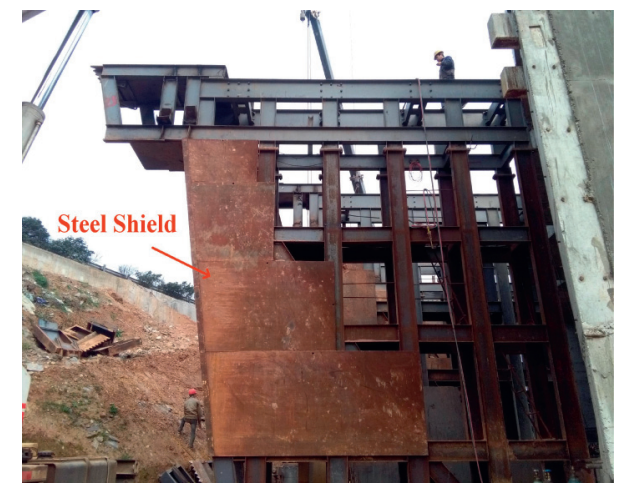

(b)

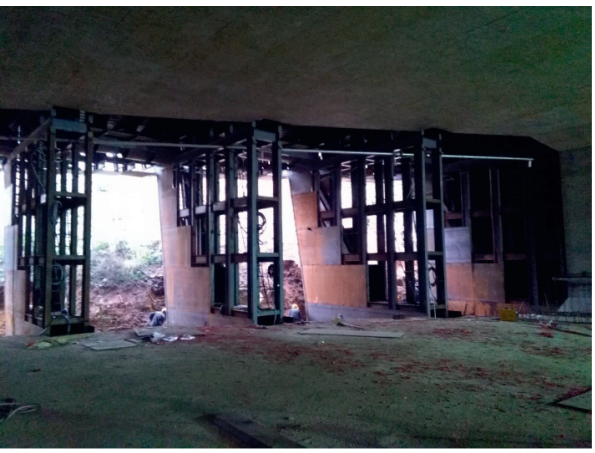

(d)

Figure 2: Steel shield and rectangular frame bridge structure: (a) completion of installation; (b) installation of steel shield; (c) exterior of shield; (d) interior of shield.

jacking construction, the cumulative local settlement and cumulative settlement of each settlement observation point of the expressway pavement greatly exceed the settlement warning value. The scene also accompanies the rebound uplift phenomenon, so shield tunneling's jacking speed should be strictly controlled. The specific reasons are as follows:
(1) The rapid jacking rate of shield tunneling in the frame bridge results in soil stress release, which forms an unloading disturbance zone around the frame bridge, resulting in excessive soil settlement.

(2) After the steel shield tunnel passes through the monitoring section, the frame bridge's soft top leads to low slurry fluidity in the grouting process. The soil 


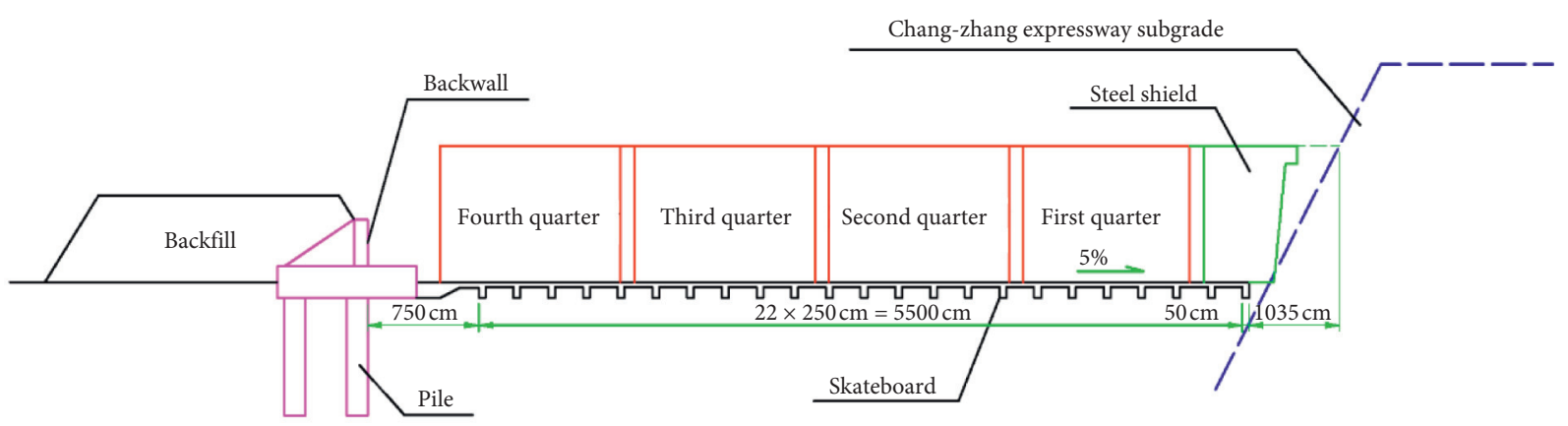

FIgURE 3: Foundation pit elevation.

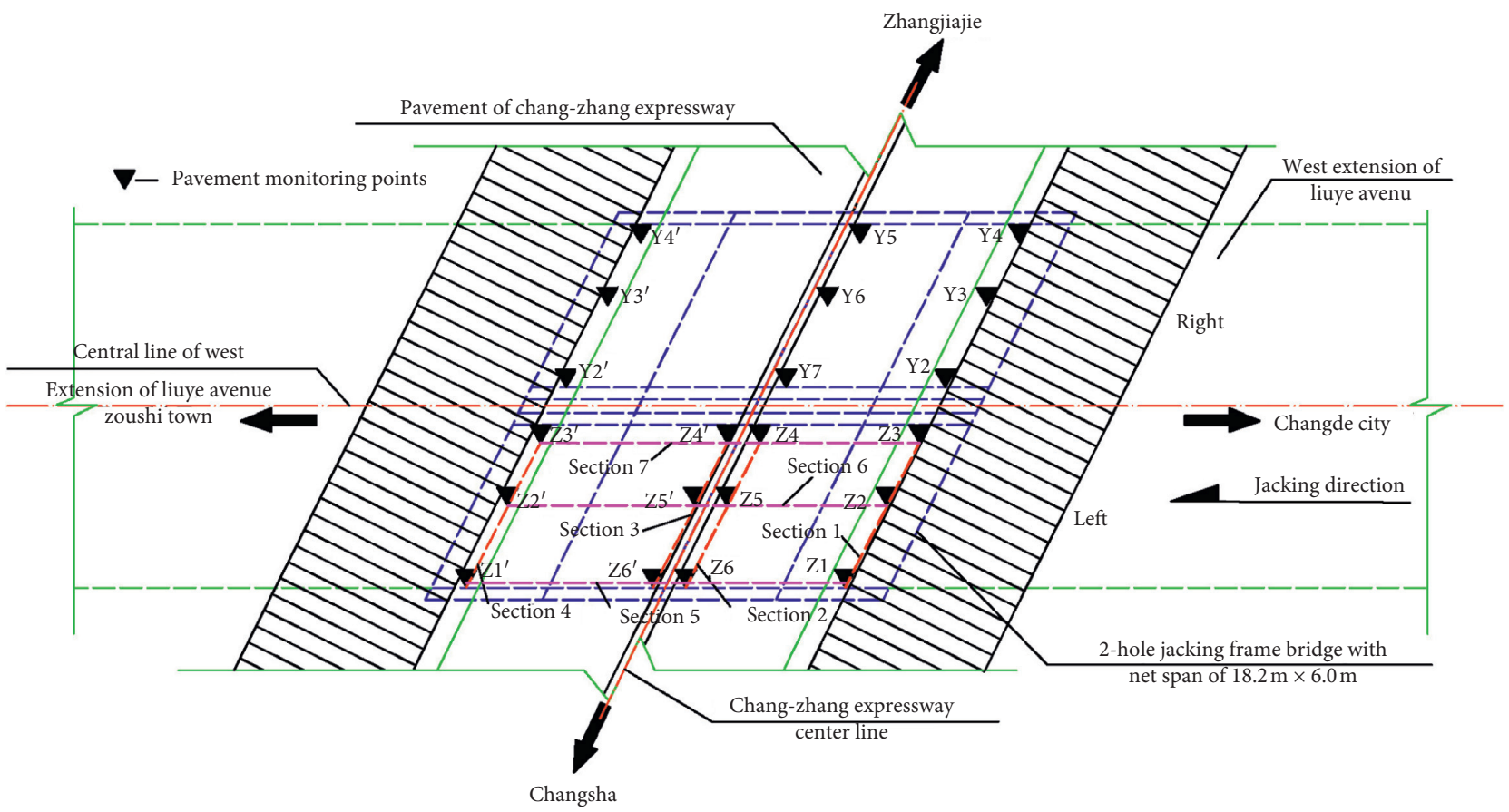

FIGURE 4: Schematic layout of observation points for pavement settlement of the frame bridge.

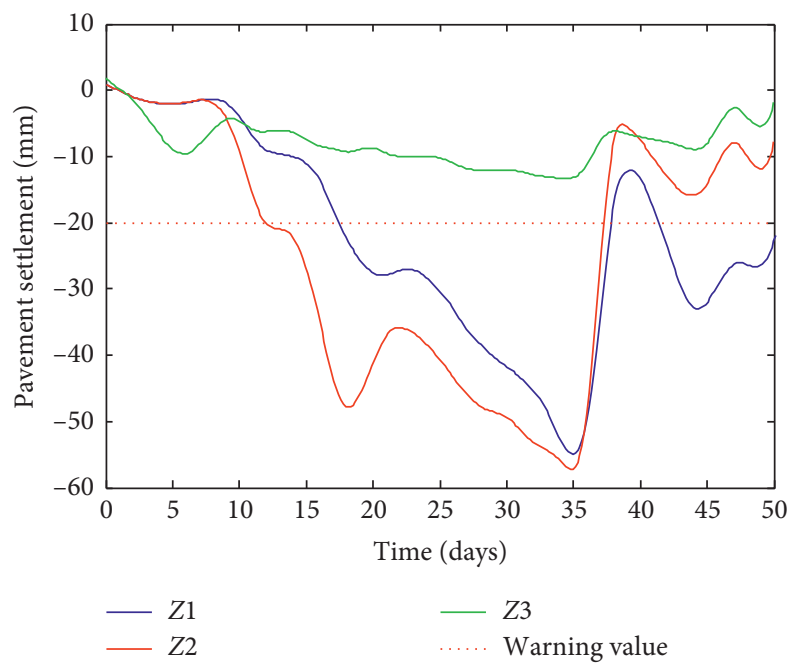

Figure 5: Cumulative settlement deformation curves of measured points; $Z 1, Z 2$, and $Z 3$. 


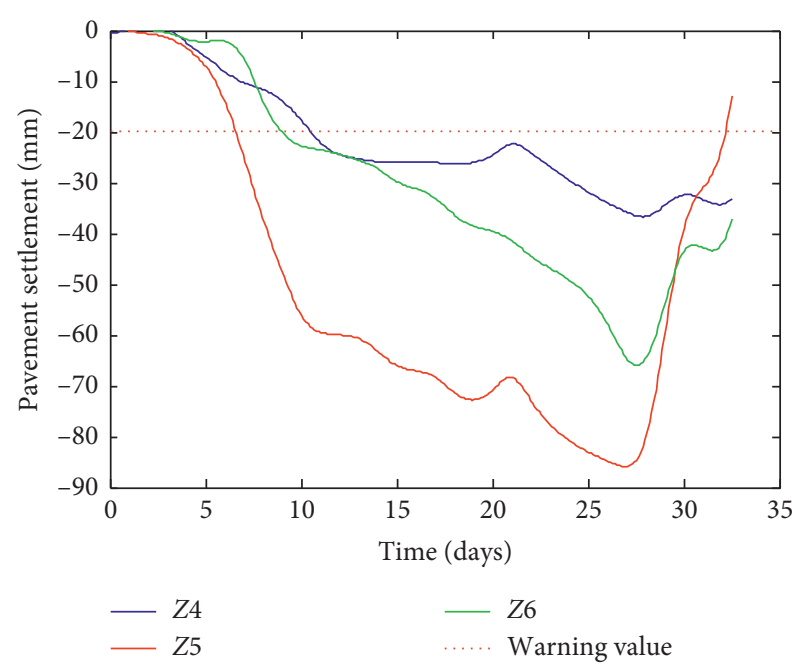

FIGURE 6: Cumulative settlement deformation curves of measured points: Z4, Z5, and Z6.

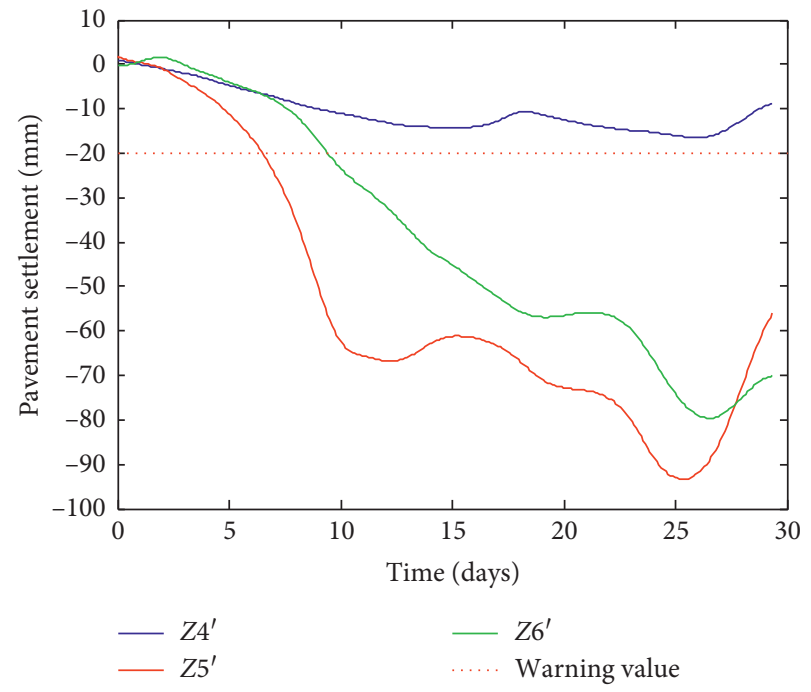

Figure 7: Cumulative settlement deformation curves of measured points: $Z 4^{\prime}, Z 5^{\prime}$, and $Z 6^{\prime}$.

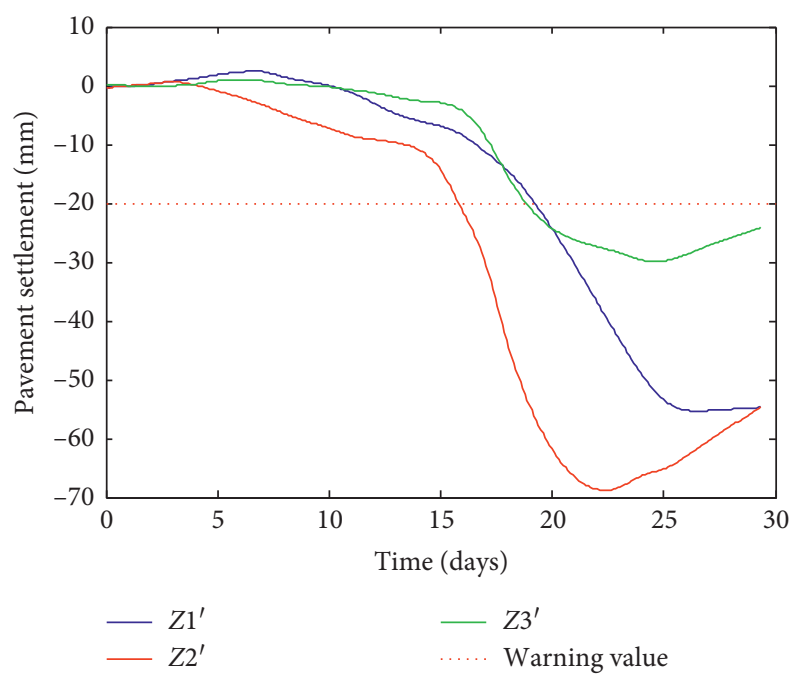

FIgURE 8: Cumulative settlement deformation curves of measured points: $Z 1^{\prime}, Z 2^{\prime}$, and $Z 3^{\prime}$.

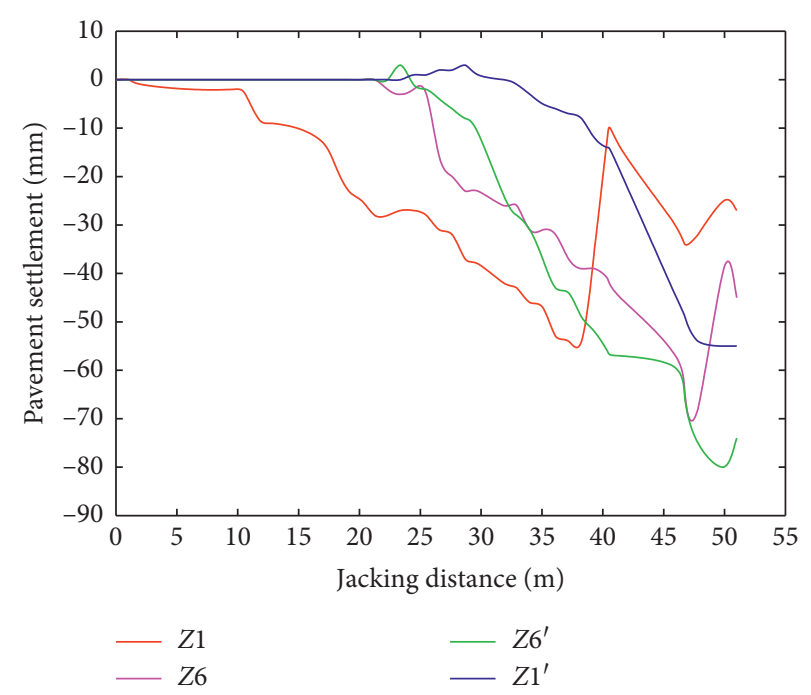

FIgURE 9: The deformation curve of the longitudinal section 5 with the jacking distance.

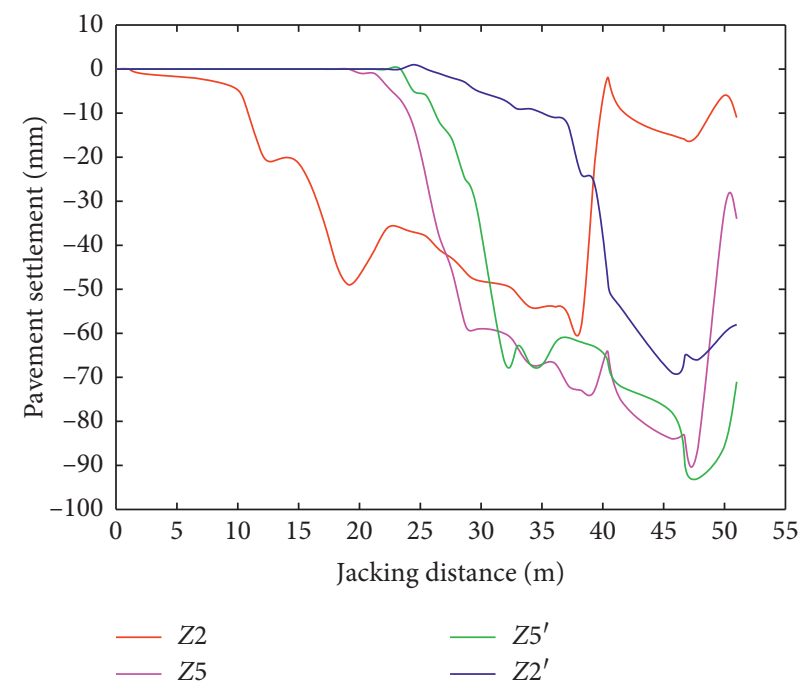

FIgURE 10: The deformation curve of the longitudinal section 6 with the jacking distance.

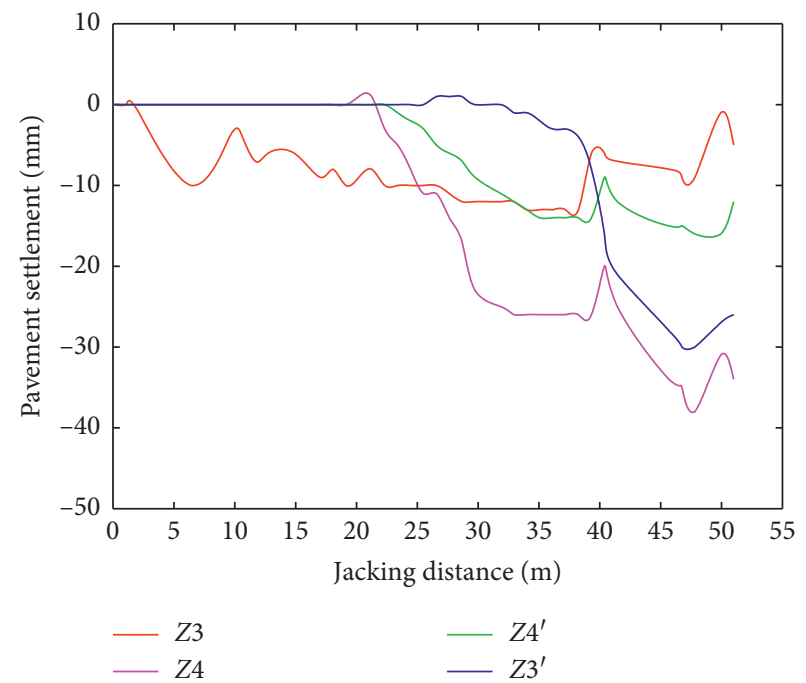

FIgURE 11: The deformation curve of the longitudinal section 7 with the jacking distance. 
above the frame bridge is extruded and uplifted by grouting, and the ground surface even appears apophysis, so the settlement value rebounds many times.

(3) In the jacking process, to adjust the jacking posture of frame bridges (or steel shield tunnels), overexcavation is unavoidable, resulting in a particular gap between the two sides of the frame bridges and the soil, thus causing pavement settlement.

(4) The contact area between the upper and lower sides of the rectangular section and the soil is extensive, and the shear disturbance zone is formed by friction and shear around the rectangular section. Besides, the rainfall in April is too abundant, and the erosion of rainwater causes soil loss, which leads to pavement settlement.

(5) The stiffness of soil is the main factor affecting the final settlement of subgrade. During the project's construction, the uneven settlement is caused by soil self-weight, horizontal jacking, and load. Also, when the soil's stiffness is not uniform, the smaller the soil's stiffness, the more sensitive the settlement change. For the subgrade with low bearing capacities such as clay and sand, the subgrade settlement with low bearing capacity can be effectively reduced by increasing the soil's stiffness.

3.2.2. Settlement Law of Transverse Pavement. Figures 12-15 show the transverse distribution of settlement and deformation of each section of the high-speed pavement caused by bridge shield construction. The axis of the left rectangular frame bridge is at $x=0 \mathrm{~m}$. As shown in the figures,

(1) The transverse settlement trough of the pavement caused by bridge shield tunneling is stable in the range of $15 \mathrm{~m}-20 \mathrm{~m}$ on both sides of the axis and symmetrical along the coordinate axis, and the line shape approximately conforms to the normal distribution.

(2) With the increase of shield tunneling and soil loss, the vertical deformation of the pavement becomes larger and larger, and the influence range of settlement trough is broader and broader.

(3) Monitoring data show that, after $T=30$ days, the soil above is obviously uplifted by grouting, the road surface begins to rise, and the vertical deformation tends to be stable. The settlement curve presents a "W" type ( $T=40$ days' settlement curve is shown in Figures 12 and 13).

3.2.3. Analysis and Suggestions. To sum up, the above phenomena's main reasons are the following: the span of the rectangular frame bridge is large, the soil erosion is severe, and the new grouting pressure range is small. Besides, the soil settlement caused by soil loss on both sides of the frame bridge decreases in the overlapping area directly above the tunnel, while the soil uplift caused by additional

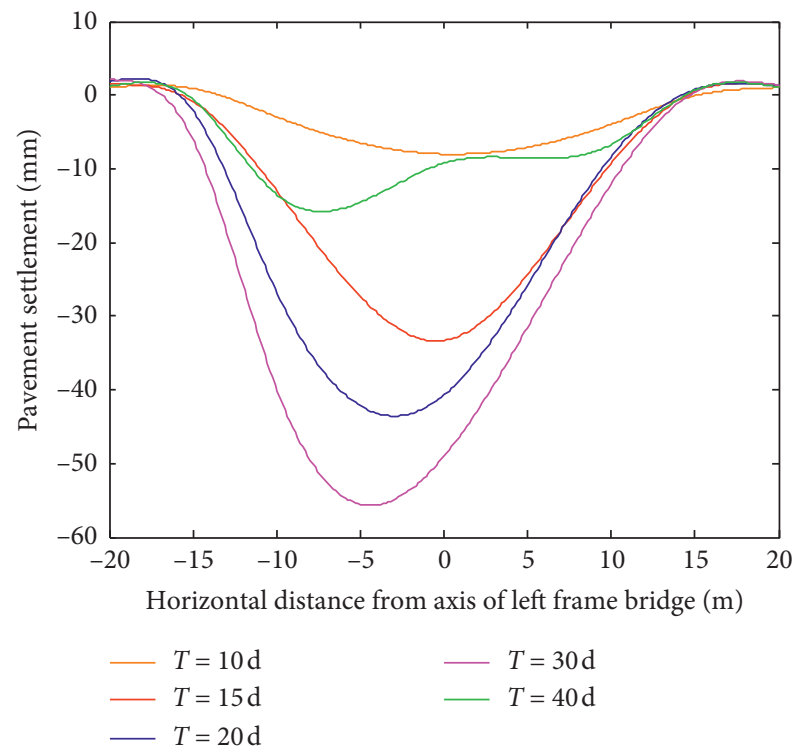

Figure 12: Settlement and deformation curve of cross section 1.

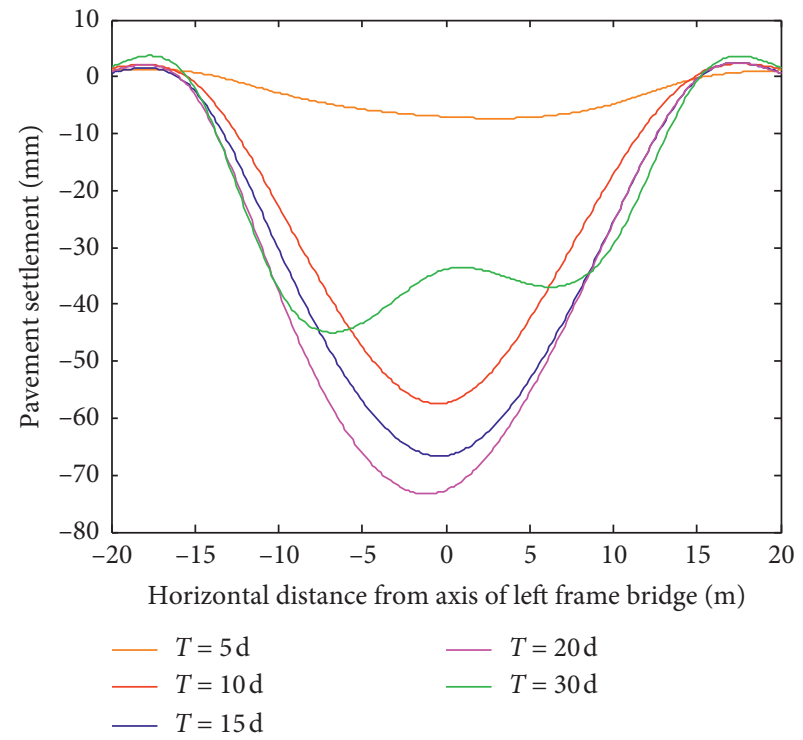

FIgURE 13: Settlement and deformation curve of cross section 2.

grouting pressure concentrates more on the top of the frame bridge, resulting in a smaller settlement of the road near the axis.

Based on the above analysis, referring to the previous research results and combining with the field situation, three feasible suggestions to reduce the pavement settlement are as follows:

(1) Controlling the thrust of a rectangular shield properly and coordinating the relationship between the thrust and the jacking speed to minimize the pavement settlement caused by soil loss.

(2) Synchronized grouting can counteract the ground subsidence caused by soil loss, so grasping the timing of synchronous grouting and controlling the 


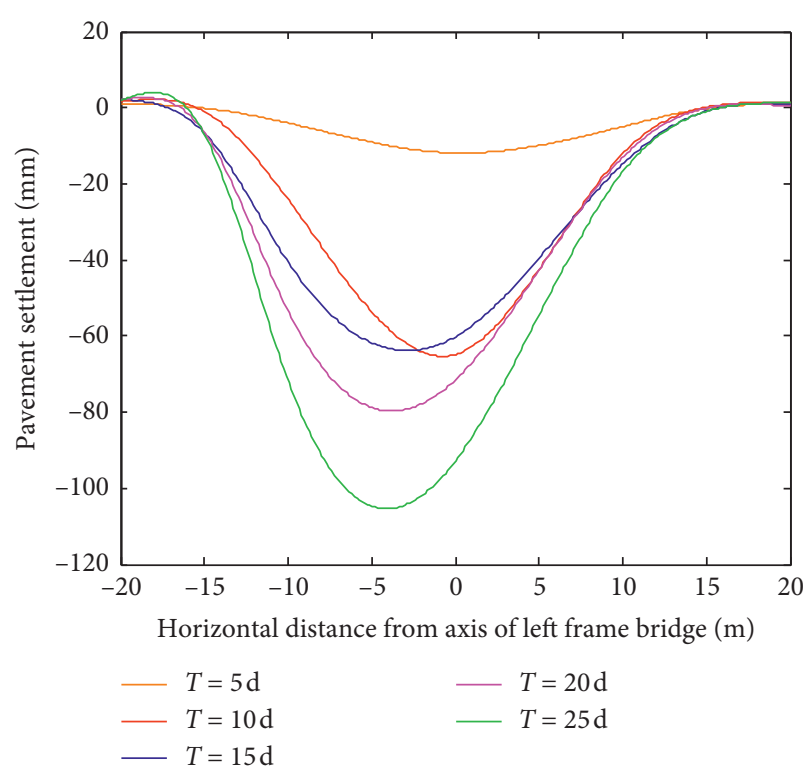

FIGURE 14: Settlement and deformation curve of cross section 3.

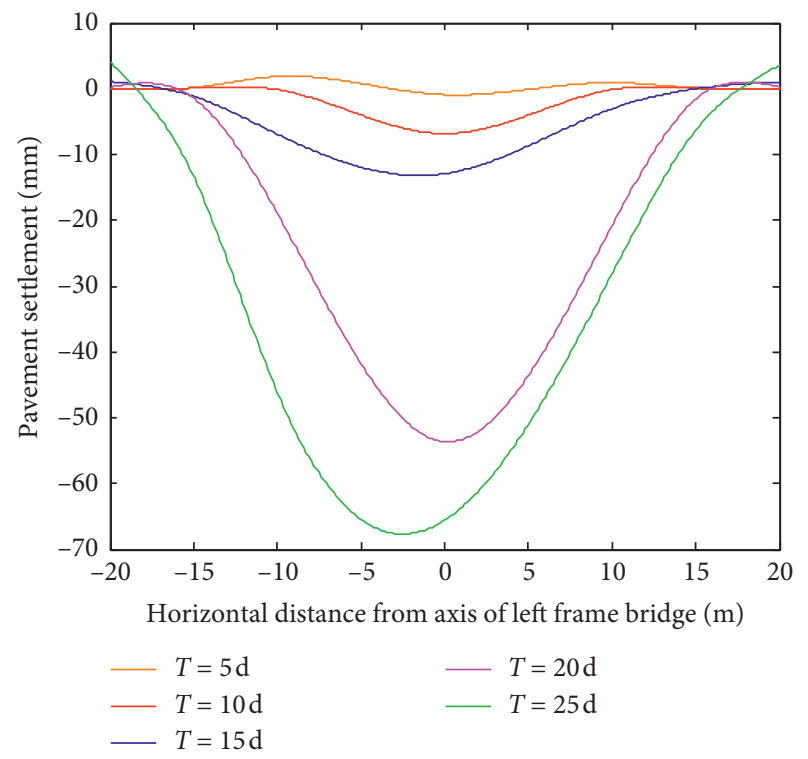

FIgURE 15: Settlement and deformation curve of cross section 4.

grouting pressure have a noticeable effect on reducing the road surface subsidence.

(3) In the process of shielding jacking, the lubricating slurry is used to reduce the contact friction between the outer surface of the steel shield and rectangular frame bridge and soil, thus effectively reducing the pavement settlement.

In summary, under the influence of complex factors such as super-shallow burial, large oblique angle, long jacking distance, and long span, how to design the jacking speed of the steel shield, reduce and control the settlement of expressway pavement, and ensure the smooth flow of an expressway is the key of this project. Therefore, it is urgent to adopt scientific methods to predict the surface subsidence deformation caused by rectangular shield jacking to reduce the risk of expressway pavement subsidence and ensure construction safety. Based on Kriging interpolation theory and field monitoring data, this paper establishes a deformation model to predict the settlement of expressway pavement caused by shielding jacking of the frame bridge.

\section{Kriging Spatiotemporal Prediction Model}

The Kriging interpolation method is a prediction method that uses structural analysis and variogram theory to calculate optimal and unbiased estimates of regionalized variables in limited space $[19,20]$. Kriging method calculates weight by introducing semivariograms with distance as independent variables because semivariograms can reflect not only the spatial structure characteristics of variables but also the random distribution characteristics of variables. In the process of data gridding, the Kriging method takes into account the spatial correlation properties of describing objects, which make the interpolation result more scientific and closer to the actual situation. It can give the interpolation error (Kriging variance) and make the interpolation's reliability clear at a glance. Although the Kriging interpolation method is widely used in the field of geological exploration and geological statistics, it has not attracted enough attention and research from experts and scholars at home and abroad in the field of geotechnical engineering.

The key to achieve space-time unification is to select the appropriate Kriging interpolation method, space-time variogram, and model parameter estimation. In the case of only considering spatial factors, the spatiotemporal autocorrelation structure is the primary concern in modeling to ensure that the selected model is effective and flexible enough to allow fitting data and estimating model parameters. The ordinary Kriging method, which is based upon the assumption of constant and unknown mean value, is the hottest interpolation analysis method in geostatistics at present [21]. In this paper, the classical Kriging spatial interpolation is extended in time and space, and the deformation prediction model is established by using the spatiotemporal variogram. The relationship between parameters and deformation is analyzed, and the calculation program and method of spatiotemporal interpolation are given.

4.1. Basic Assumptions. Time-series data collected in deformation monitoring operations are generally unequal spacing, and the measurement frequency varies with the different construction stages of shield jacking. Therefore, when using the regression model, grey model, artificial neural network model, and other methods to analyze and process such measurement data, unless measured on time according to the experimental research plan, the nonequidistant measurement data can only be converted into equidistant measurement data by the mathematical method. Then the next work can be carried out. The application of the Kriging interpolation prediction model can solve this problem very well. It can avoid considering the influence of 
each factor in construction in turn, analyze the correlation between the factors, and improve the prediction accuracy.

In order to simplify the calculation process of the spatiotemporal Kriging interpolation prediction model, it is assumed that

(1) Deformation data is the macroscopic reflection of stratum deformation law, and the prediction value of deformation analysis only carries out in-depth data mining of geological body deformation law.

(2) The ultimate stress and strain during shield jacking construction of the rectangular frame bridge are the result of interaction and comprehensive action of external and internal conditions and various factors in the geological body.

(3) The interaction, interaction, and nonlinearity of the factors affecting the geological body can be established, but the deformation prediction model can be fitted.

4.2. Fundamental Theory. Kriging interpolation algorithm is the best linear unbiased estimation algorithm for spatial variation study and spatial interpolation. Kriging interpolation method considers not only the mutual relation between the location of the point to be evaluated and the location of known data, but also the spatial correlation of variable. It is assumed that regionalized variables are not mutually independent, have absolute randomness and structural characteristics, and meet second-order stationary and intrinsic stationary.

Basic mathematical model of the Kriging interpolation method is shown as [20]

$$
Z^{\prime}\left(X_{0}\right)=\sum_{i=1}^{n} \lambda_{l} Z\left(X_{i}\right)
$$

where $Z^{\prime}\left(X_{0}\right)$ denotes the estimation value of predicted point; $Z\left(X_{i}\right)$ denotes the value of reference points in the region adjacent to the predicted point involved in prediction; $\lambda_{i}$ denotes Kriging weight coefficient, which is defined depending on the calculated results of variation function under the conditions of unbiasedness and minimum variance property.

Equation (1) is the linear combination of $n$ values; the principle of the Kriging method is to ensure that the estimator is unbiased and calculates $n$ weight coefficients $\sigma_{E}^{2}$ under the premise of the estimated variance which is minimum.

$$
\left\{\begin{array}{c}
E\left[Z^{\prime}\left(X_{0}\right)-Z\left(X_{0}\right)\right]=0 \Longrightarrow \sum_{i=1}^{n} \lambda_{l}=1 \\
\sigma_{E}^{2}=E\left[Z^{\prime}\left(X_{0}\right)-Z\left(X_{0}\right)\right]^{2}=\operatorname{Min}
\end{array}\right\} .
$$

Under the unbiasedness condition, it is a problem that conditional extremum is calculated by the Lagrangian multiplier method in order to obtain the minimum estimated variance.

$$
F=\sigma_{E}^{2}-2 \mu\left(\sum_{i=1}^{n} \lambda_{l}-1\right),
$$

and $F$ is $(n+1)$ function of $n$ weight coefficients and $\mu$, where it is first to calculate the partial derivative of $F$ from $\lambda_{i}$ and $\mu$ and finally obtain the Kriging equation set expressed by the value of semivariable function:

$$
\left\{\begin{array}{c}
\sum_{j=1}^{n} \lambda_{j} y_{i, j}+\mu=y_{i, 0}, \quad(i=1,2, \ldots, n) \\
\sum_{j=1}^{n} \lambda_{j}=1
\end{array}\right\},
$$

where $y_{i, j}=y\left(x_{i}, y_{j}\right)=y\left(x_{i}-y_{j}\right)$.

4.3. Semivariogram Theoretical Model. Semivariable function or semimutation function is derived from variance concept in spatial statistics [22]. 1/2 of difference variance between the $Z(x)$ value and $Z(x+h)$ value of regionalized variable $Z(X)$ on point $x$ and point $x+h$ is defined as a semimutation function of regionalized variable $Z(x)$ along the $x$-axis, denoted as $\gamma(h)$, namely,

$$
\gamma(h)=\frac{1}{2} \operatorname{Var}[Z(X)-Z(X+h)]^{2} .
$$

The variational function equation is shown in Figure 14. The computational formula for trial semivariable function is

$$
\gamma^{*}(h)=\frac{1}{2 N(h)} \sum_{i=1}^{N(h)}\left[Z\left(X_{i}\right)-Z\left(X_{i}+h\right)\right]^{2} .
$$

In order to estimate the unknown values of the regionalized variable, it is necessary to fit the semivariable trial function into the corresponding theoretical semimutation function model. Semimutation function models provided by typical Kriging algorithm include Gaussian, linear, spherical, damping sine, and exponential model (spherical, exponential, and Gaussian models are shown in Figure 16). The spherical variogram model near the origin is linearity; the exponential variogram model is a straight line, while the Gauss variogram model is a parabola. Spherical model is utilized in consideration that the paper is applied to the deformation prediction of ground. In this way, it not only considers the randomness of reservoir parameters, but also considers its correlation and obtains the best linear unbiased interpolation and the interpolation variance under meeting the condition of minimum interpolation variance. Specific model expression and function graph are shown as follows: 


$$
\gamma(h)=c \cdot \operatorname{Sph}\left(\frac{h}{a}\right)= \begin{cases}0, & h=0, \\ c_{0}+c \cdot\left[\frac{3 h}{2 a}-\frac{1}{2}\left(\frac{h}{a}\right)^{3}\right], & 0<h \leq a, \\ c_{0}+c, & h>a,\end{cases}
$$

where $c_{0}$ denotes Nugget, $\left(c_{0}+c\right)$ denotes Sill, $c$ denotes Partial Sill, $a$ denotes range, and $h$ denotes lag distance. Variation function equations are shown in Figure 17.

4.4. Spatiotemporal Interpolation. Spatial Kriging can only estimate the deformation within the unknown region at a particular time, and it is necessary to conduct spatiotemporal Kriging interpolation if deformation at any position and any time is to be estimated. In the process of shield tunneling, changes in monitoring point layout, data collection, and displacement value are not only the simple space-time changes but also the space-time unification. The paper selects the ordinary Kriging method to realize the space-time data interpolation, and the computational formula is shown as follows:

$$
Z^{*}\left(s_{0}, t_{0}\right)=\sum_{i=1}^{n} \lambda_{i} Z\left(s_{i}, t_{i}\right)
$$

where $Z^{*}\left(s_{0}, t_{0}\right)$ denotes the estimated value at the spacetime point $\left(s_{0}, t_{0}\right), \lambda_{i}$ denotes the weight coefficient adjacent to observed value $Z\left(s_{i}, t_{i}\right)$, and the Lagrangian coefficient $\mu$ is introduced to deduce

$$
\left(\begin{array}{cccc}
\gamma_{11} & \cdots & \gamma_{1 n} & 1 \\
\vdots & \vdots & \vdots & \vdots \\
\gamma_{n 1} & \gamma_{m} & \cdots & 1 \\
1 & \cdots & \cdots & 0
\end{array}\right)\left(\begin{array}{c}
\lambda_{1} \\
\vdots \\
\lambda_{n} \\
\mu
\end{array}\right)=\left(\begin{array}{c}
\gamma_{01} \\
\vdots \\
\gamma_{0 n} \\
1
\end{array}\right) .
$$

Weight coefficient $\lambda$ in (9) can be obtained by (1) and then substituted into (8) to obtain the interpolate estimation at any point within the survey region.

The necessary steps of spatiotemporal interpolation are as follows:

(1) Calculating the spatiotemporal experimental variation function and estimating the parameters of spatiotemporal variation model.

(2) Determining the optimal time-space variogram and related parameters.

(3) Calculating $k 1, k 2$, and $k 3$ and calculating the spatiotemporal variogram model.

(4) The predicted value calculated by (8) and (9).

The flow chart of the algorithm is designed as shown in Figure 18.

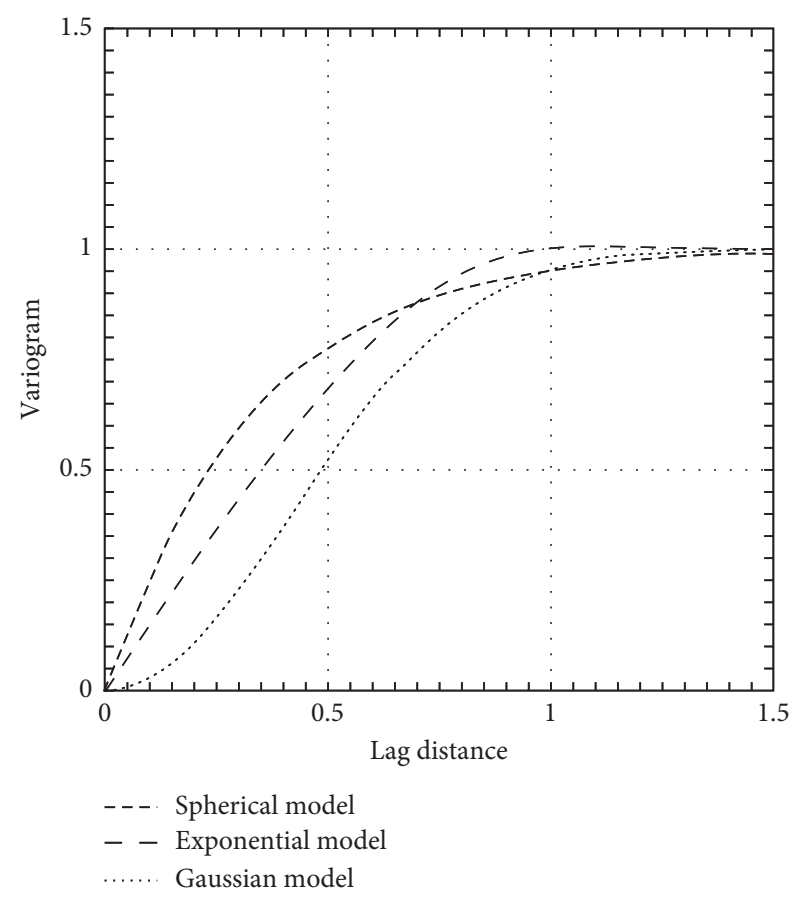

FIgURE 16: Semivariogram theoretical model diagram.

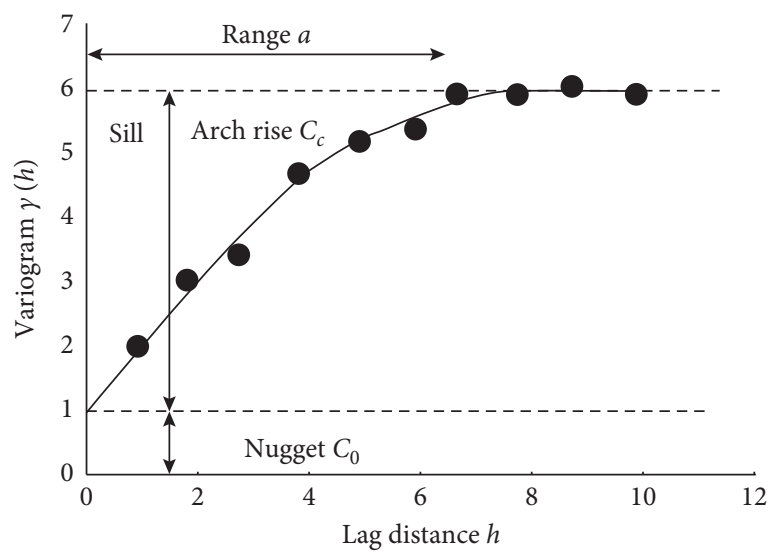

Figure 17: Variation function equations.

\section{Prediction Analysis}

5.1. Calculation Scheme. The field-test data are divided into three components and then imported into the Kriging spatiotemporal model for calculation. The first group: based on the measured data of $Z 1$ and $Z 1-1$ monitoring points, the settlement values of $Z 1-2$ monitoring points are predicted. Then the settlement values of $Z 1-3$ and $Z 6$ monitoring points are predicted by analogy $(Z 1, Z 1-1, Z 1-2, Z 1-3$, and $Z 6$ are arranged in rows along with the longitudinal road interval of 5 meters, respectively). The second group: based on the measured data of $Z 2$ and $Z 2-1$ monitoring points, the settlement values of $Z 2-2$ monitoring points are predicted, and the settlement values of $Z 2-3$ and $Z 5$ monitoring points are predicted by analogy once again $(Z 2, Z 2-1, Z 2-2, Z 2-3$, and $Z 5$ are arranged in rows along with the longitudinal road 


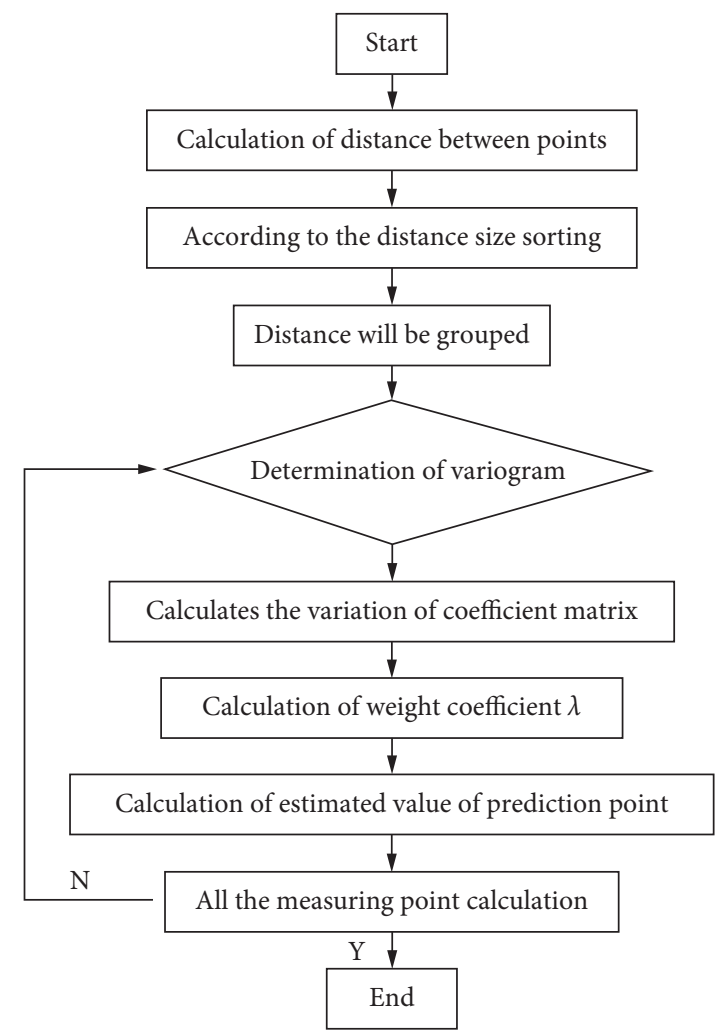

FIGURE 18: Program design flow chart.

TABLE 1: Grouping of monitoring points.

\begin{tabular}{|c|c|c|c|c|c|c|}
\hline Grouping & $\begin{array}{c}\text { Measured point } \\
1\end{array}$ & $\begin{array}{c}\text { Measured point } \\
2 \\
\end{array}$ & $\begin{array}{c}\text { Prediction point } \\
1\end{array}$ & $\begin{array}{c}\text { Prediction point } \\
2\end{array}$ & $\begin{array}{c}\text { Measured point } \\
\text { 3/prediction point } 3\end{array}$ & $\begin{array}{l}\text { Longitudinal spacing of } \\
\text { measuring points }(\mathrm{m})\end{array}$ \\
\hline First group & $Z 1$ & $Z 1-1$ & $Z 1-2$ & $Z 1-3$ & $Z 6$ & 5 \\
\hline $\begin{array}{l}\text { Second } \\
\text { group }\end{array}$ & $Z 2$ & $Z 2-1$ & $Z 2-2$ & $Z 2-3$ & $Z 5$ & 5 \\
\hline $\begin{array}{l}\text { Third } \\
\text { group }\end{array}$ & $Z 3$ & Z3-1 & $Z 3-2$ & $Z 3-3$ & $Z 4$ & 5 \\
\hline
\end{tabular}

interval of 5 meters, respectively). The third group: based on the measured data of $\mathrm{Z} 3$ and Z3-1 monitoring points, the settlement values of $Z 3-2$ monitoring points are predicted, and the settlement values of $Z 3-3$ and $Z 4$ monitoring points are predicted by analogy once again $(Z 3, Z 3-1, Z 3-2, Z 3-3$, and $Z 4$ are arranged in rows along with the longitudinal road interval of 5 meters, respectively). Theoretical analysis and practice show that the prediction error is proportional to the nugget value $\left(C_{0}\right)$, and the range has a more significant impact on the prediction error, while the sill value $\left(C_{0}+C\right)$ has a limited impact on the prediction results. The grouping of each group of monitoring points and the parameters related to the variation function is shown in Tables 1 and 2, respectively.

5.2. Prediction Analysis. The calculation results are shown in Figures 19-21.

Since the Kriging prediction model in this paper is based upon the settlement monitoring data from this project, whether the prediction outcomes meet the actual situation
TABLE 2: Spatial variogram parameters.

\begin{tabular}{lcccc}
\hline Grouping & Prediction section & Range $a / m$ & $C_{0}$ & $C$ \\
\hline First group & $Z 6$ & $\mathrm{~s}$ & 0.10 & 0.50 \\
Second group & $Z 5$ & 18 & 0.01 & 0.15 \\
Third group & $Z 4$ & 15 & 0.10 & 2.00 \\
\hline
\end{tabular}

should be cross-validated, and the prediction model should be tested and evaluated. In this paper, the $R_{\mathrm{MS}}$ formula is used to calculate the residual prediction error $\left(R_{\mathrm{MSE}}\right)$, and the mean error $\left(R_{E}\right)$ based on the residual calculation results is obtained. We use the above indicators as the test criteria to test the validity of the prediction results. The smaller the test criteria value is, the more accurate the prediction results will be, and the prediction value will be closer to the actual value. If the average error is close to " 0 ," we consider the estimate to be unbiased. The correlation coefficient $R^{2}$ is also calculated in this section, which is closer to " 1 ," and the linear correlation measurement curve of the prediction curve and the actual value is higher. 


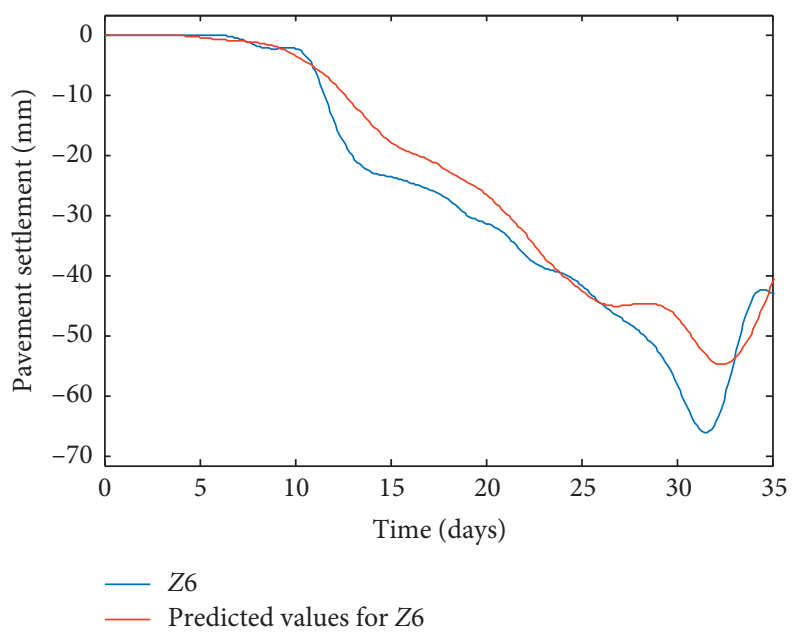

Figure 19: The contrast of the measured and predicted values for $Z 6$.

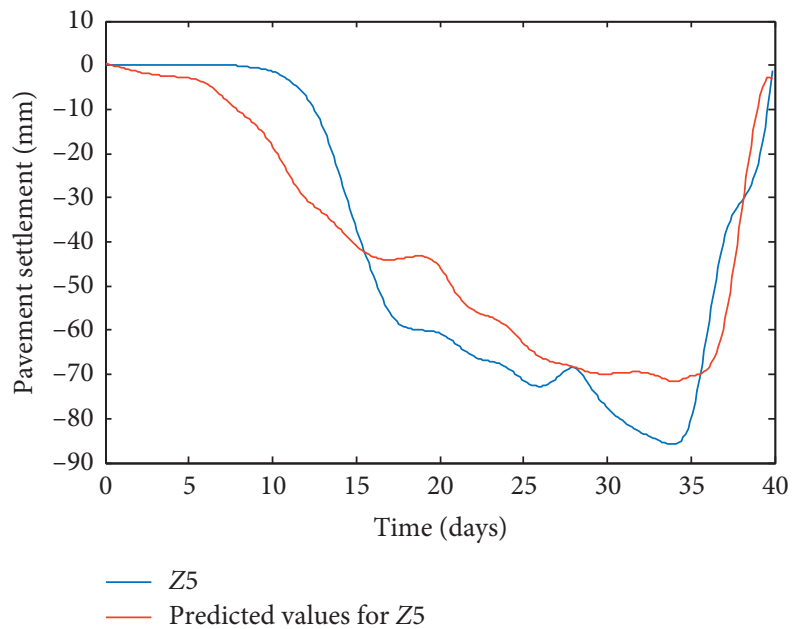

Figure 20: The contrast of the measured and predicted values for $Z 5$.

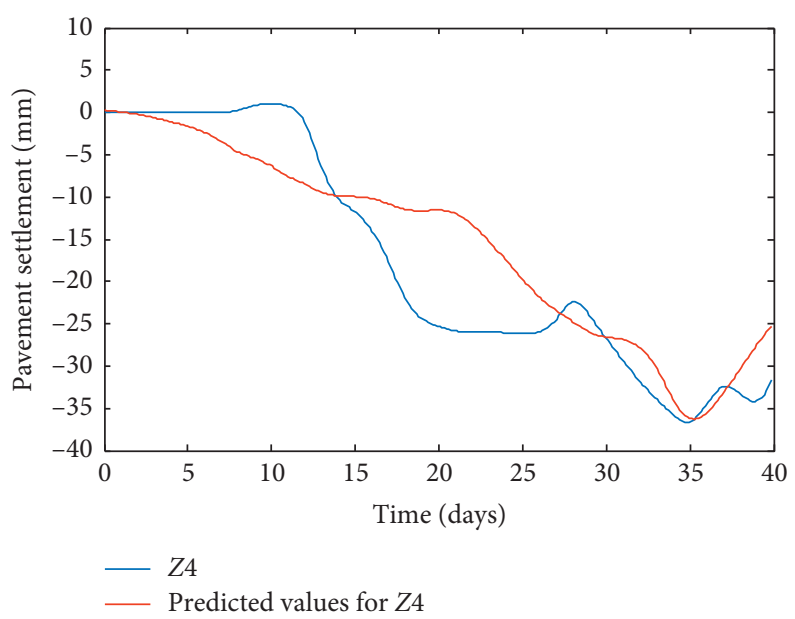

FIgURE 21: The contrast of the measured and predicted values for $Z 4$.

The calculation shows that the three prediction accuracy evaluation indexes obtained from Kriging spatiotemporal unified interpolation model described within this paper are shown in Table 3. Root-mean-square error is $12.82 \mathrm{~mm}$. The average error is $2.97 \%$, and the correlation coefficient is 0.78 . It is proved that this prediction model has absolute 
TABle 3: Precision evaluation.

\begin{tabular}{lcccc}
\hline Grouping & Prediction section & Root-mean-square error $\left(R_{\mathrm{MSE}}\right)$ & Correlation coefficient $\left(R^{2}\right)$ & Average error $/ R_{E}(\%)$ \\
\hline First group & $Z 6$ & 5.86 & 0.94 & 2.97 \\
Second group & $Z 5$ & 12.82 & 0.87 & 0.33 \\
Third group & $Z 4$ & 6.53 & 0.78 & 1.75 \\
\hline
\end{tabular}

prediction accuracy and feasibility and validity in practical engineering applications.

\section{Conclusions}

Based on Kriging spatiotemporal prediction model, this paper studies the pavement settlement deformation caused by shield jacking of the rectangular shield frame bridge in ultra-shallow soft soil stratum, combined with the monitoring data of the field-test section, and draws the following conclusions:

(1) Through on-site monitoring, the law of settlement and deformation of longitudinal and transverse expressway pavement sections during jacking construction is studied. The causes of a substantial settlement and local settlement rebound are analyzed, and the fundamental law of ground settlement with time is summarized.

(2) The transverse settlement trough of the pavement caused by the jacking construction of rectangular bridge shield tunneling is stable within $15 \mathrm{~m}-20 \mathrm{~m}$ on both sides of the axis and symmetrical along the axis, and the line shape approximately conforms to the normal distribution. The influence range of settlement trough becomes larger and larger with shield jacking, and the final settlement curve presents a "W" shape.

(3) By comparing with the measured surface settlement curve, the prediction curve based on Kriging spatiotemporal prediction model is in good agreement with the measured data, which can reflect the development process of pavement deformation during shield jacking to a certain extent.

However, there is still a gap between the predicted value of the Kriging prediction method and the measured value, which is related to the jacking rate, jacking thrust, grouting control, and traffic load of ultra-shallow buried steel shield tunneling. Therefore, the soil deformation caused by jacking construction of ultra-shallow rectangular bridge shield tunneling considering multifactor coupling needs further study.

\section{Data Availability}

All data generated or analyzed during this study are included in this article.

\section{Additional Points}

(1) The settlement deformation law of the longitudinal and transverse sections of the expressway pavement during the jacking construction process is discussed, and the reasons for the large settlement and rebound are analyzed. (2) Considering the time effect, the ordinary Kriging model is interpolated in time and space, and the spatiotemporal prediction model is established. (3) The Kriging spatiotemporal prediction model is applied to predict the settlement of expressway pavement.

\section{Conflicts of Interest}

The authors declare no conflicts of interest.

\section{Acknowledgments}

This study was supported by the National Natural Science Foundation of China (Grant no. 51678226); the Natural Science Foundation of Hunan Province (Grants nos. 2019JJ50030 and 2020JJ5023); the Science and Technology Innovation Project of Yiyang City (Grant no.: 2019YR02); and the Scientific Research Projects of Hunan Education Department (Grants nos 18C0850 and 19C0358). These supports are greatly appreciated.

\section{References}

[1] R. L. Sterling, "Developments and research directions in pipe jacking and microtunneling," Underground Space, vol. 5, no. 1, p. 1, 2020.

[2] M. P. O'Reilly and C. D. Rogers, "Ground movement associated with pipe jacking and trenching," in Proceedings of the 5th Internatioanl No-Dig'90 Conference, pp. B1.1-B1.8, Rotterdam, Netherlands, 1990.

[3] C. Rogers and D. Chapman, "Ground movement caused by trenchless pipe installation techniques," in Proceedings of the Transportation Research Board, 74th Annual Meeting, Washington, DC, USA, 1995.

[4] M. A. Marshall, Pipe-Jacked Tunnelling: Jacking Loads and Ground Movements, University of Oxford, Oxford, UK, 1998.

[5] S. L. Shen, Q. L. Cui, C. E. Ho, and Y. S. Xu, "Ground response to multiple parallel microtunneling operations in cemented silty clay and sand," Journal of Geotechnical Geoenvironment Engineering, vol. 142, no. 5, pp. 1-16, Article ID 04016001, 2016.

[6] L. Y. Cheng, S. T. Ariaratnam, and S. X. Chen, "Analytical solution for predicting ground deformation associated with pipe jacking," Journal of Pipeline System Engineering Practice, vol. 8, no. 3, pp. 1-11, Article ID 04017008, 2017.

[7] F. Matsumoto, T. Morita, and E. Sakai, "Application of a rectangular pipe jacking machine for long distance and curved pipeline construction," in Proceedings of the ISTT No-Dig Conference, p. 22, Singapore, November 2010.

[8] J. Landers and U. K. Large, "Highway underpass installed by horizontal jacking," Civil Engineering, vol. 82, pp. 27-29, 2012.

[9] H. Wang, W. M. Qin, and Y. Y. Jiao, "Stability assessment for highway with large-span box culvert jacking underneath: a 
case study," Canadian Geotechnical Journal, vol. 50, no. 6, pp. 585-594, 2013.

[10] R. D. Wang, "Calculating methods of soil deformation induced by rectangular pipe jacking construction," Journal of Jiamusi University (Natural Science Edition), vol. 32, no. 5, pp. 711-714, 2014.

[11] C. M. Deng, J. M. Peng, and G. H. Shen, "Discussion on control methods of ground surface settlement caused by rectangular pipe jacking construction in soft soils," Chinese Journal of Underground Space and Engineering, vol. 12, no. 4, pp. 1002-1007, 2016.

[12] F. L. Zhang, X. Y. Kou, and J. Huang, "Application of Peck Formula and its modified versions in ground settlement prediction during quasi-rectangular tunneling," Modern Tunnelling Technology, vol. 53, no. S1, pp. 195-200, 2016.

[13] J. Li, "Key technologies and applications of the design and manufacturing of non-circular TBMs," Engineering, vol. 3, no. 6, pp. 905-914, 2017.

[14] J. B. Si, Y. H. Zhu, C. Ji, and S. H. Zhou, "Measurement and analysis of vertical deformation of stratum induced by quasirectangular shield tunneling in soft ground," Chinese Journal of Rock Mechanics and Engineering, vol. 32, no. 6, pp. 256264, 2017.

[15] X.-Y. Li and G.-B. Liu, "A complex variable solution for rectangle pipe jacking in elastic half-plane," Mathematical Problems in Engineering, vol. 2017, Article ID 5713063, 7 pages, 2017.

[16] P. Di Mascio, G. Loprencipe, L. Moretti, L. Puzzo, and P. Zoccali, "Bridge expansion joint in road transition curve: effects assessment on heavy vehicles," Applied Sciences, vol. 7, no. 6, p. 599, 2017.

[17] G. Wei, X. H. Zhang, and Y. F. Xu, "Deriving vertical displacement of ground due to quasi-rectangular shield tunneling considering multiple factors," Chinese Journal of Rock Mechanics and Engineering, vol. 37, no. 1, pp. 199-208, 2018.

[18] X. H. Zhang, J. X. Cheng, Y. Bai, A. Chen, and D. Z. Huang, "Ground surface deformation induced by quasi-rectangle EPB shield tunneling," Journal of Zhejiang University (Engineering Science), vol. 52, no. 2, pp. 317-324, 2018.

[19] Y. J. Xu, Y. J. Wang, C. Feng, Z. W. Liu, and J. Zhu, "Research on ground deformation caused by rectangular pipe jacking construction," Chinese Journal of Underground Space and Engineering, vol. 14, no. 1, pp. 192-199, 2018.

[20] R. Gebbers, N. Marwan, and E. Sillmann, MATLAB ${ }^{\circledR}$ Recipes for Earth Sciences, pp. 217-223, Springer, Berlin, Germany, 2003.

[21] M. H. Trauth, MATLAB Recipes for Earth Sciences, Springer, Berlin, Germany, 2006.

[22] M. Trauth and E. Sillmann, "MATLAB ${ }^{\circledR}$ and design recipes for earth sciences: how to collect, process and present geoscientific information," in Proceedings of the EGU General Assembly Conference, pp. 22-27, Vienna, Austria, April 2013. 